Saudi Journal of Medicine

Abbreviated Key Title: Saudi J Med ISSN 2518-3389 (Print) |ISSN 2518-3397 (Online)

\title{
Predicting the Need for ICU Care in Patients with Acute Ischemic Stroke
}

\author{
Aziza Khalifa $^{1}$, Adil Al Kharusi ${ }^{2}$, Abdullah Al Jadidi ${ }^{3}$, Mohammed Azharuddin Malik ${ }^{4}$, Rashid M Khan ${ }^{5 *}$ \\ ${ }^{1} 4^{\text {th }}$ Year Anesthesia Resident, Oman Medical Specialty Board, Muscat, Sultanate of Oman \\ ${ }^{2} \mathrm{MD}$, Department of Anesthesia \& ICU, Khoula Hospital, Muscat, Sultanate of Oman \\ ${ }^{3} \mathrm{MD}$, Fellow in Neuroanesthesia \& Neurocritical Care (UK), Department of Anesthesia \& ICU, Khoula Hospital, Muscat, Sultanate of Oman \\ ${ }^{4} \mathrm{MD}$, DM, FACC, Department of Cardiology, Jawahar Lal Nehru Medical College, AMU, Aligarh, India \\ ${ }^{5}$ Senior Consultant, Department of Anesthesia \& ICU, Khoula Hospital, Muscat, Sultanate of Oman
}

DOI: $10.36348 /$ sjm.2020.v05i12.001 $\quad$ | Received: 16.11 .2020 | Accepted: 27.11 .2020 | Published: 05.12 .2020

*Corresponding Author: Rashid M Khan

\section{Abstract}

Specialized stroke units are known to provide best care for stroke patients. However in their absence, patients are often shifted to regular intensive care units that are already overburdened. We carried out a retrospective study to identify ischemic stroke patients who can be safely cared outside the intensive care unit (ICU) using National Institute of Health Stroke Scale (NIHSS) score as predictor of serious morbidity and mortality. We analyzed 50 ischemic stroke patients with complete records of NIHSS score and well-documented complications, if any, while being nursed in our ICU. The results show that patients having NIHSS score between 0-4 rarely have any complications other than very trivial ones'. These patients can be cared in high dependency units or stroke wards with dedicated trained nursing staff. Furthermore we noted that the patients at maximum risk of serious morbidity and mortality have NIHSS score greater than 15 . These patients frequently need ventilatory/ hemodynamic support or management of cerebral edema and elevated ICP and hence justify ICU support.

Keywords: Ischemic stroke, intensive care unit, national institute health stroke scale.

Copyright ( ) 2020 The Author(s): This is an open-access article distributed under the terms of the Creative Commons Attribution 4.0 International License (CC BY-NC 4.0) which permits unrestricted use, distribution, and reproduction in any medium for non-commercial use provided the original author and source are credited.

\section{INTRODUCTION}

Globally, stroke is the second leading cause of death. Fortunately, significant progress has been made in early and effective management of these patients resulting in reduced mortality from stroke [1-3]. This has been mainly attributed to the focused care of these patients in specialized stroke units. However, less widely understood is the role of intensive care unit (ICU) management in stroke patients [4].

Patients are generally cared in the ICU for a better outcome from stroke. ICU interventions in these patients usually include osmotic therapy/ surgical decompression for cerebral edema, blood pressure titration/reversal of coagulopathy in patients with hemorrhagic transformation or blood pressure augmentation/early antiplatelet therapy in progressive stroke patients [1]. However, ICU care management of stroke patients with none of these morbidities may not justify their admission into ICU.

The National Institutes of Health Stroke Scale (NIHSS) is a scoring system to help healthcare providers to evaluate the stroke severity [5]. As per our present institution policy, all patients receiving alteplase therapy for stroke are admitted to the ICU irrespective of their NIHSS score. We undertook a retrospective analysis of all stroke patients admitted to our ICU between January 2017- January 2020 to correlate their NIHSS score to various complications in the post alteplase therapy period. The aim of this study was to identify that NIHSS score below which no major complications were noted so that in future all these patients could be cared for in the neurology ward thereby avoiding ICU admission and wasting precious hospital resources.

\section{METHODOLOGY}

The ICU at Khoula Hospital at Muscat is a 30bed facility. This ICU basically caters to surgical and neurological patients including neurology. The ICU is run by a group of anesthesiologists and Intensivist with support from medicine/neurology departments.

Following approval from the Department Management Board, data of all ischemic stroke patients admitted in the ICU within a specified study period (January 2017-January 2020) were retrieved from the hospital's e-records and analyzed. The parameters that were recorded included patient's demographic data, NIHSS score, complications, and final outcome. 
We had 69 patients who received alteplase therapy on admissions to our hospital during the study period. Of these, only 50 were found to be eligible for inclusion in our retrospective study as per the study design.

\section{DATA ANALYSIS}

All data that were retrieved from patient's file were entered into SPSS version 26.0 and analyzed for their statistical significance. Quantitative data has been analyzed using one-way ANOVA or the independent sample $\mathrm{t}$ test, whichever was applicable. Categorical data was analyzed with Chi-square test. $\mathrm{P}$ value $<0.05$ was considered significant.

\section{RESULTS}

During the three-year study period, there were 3025 admissions into our ICU. Of these, 69 patients had documented ischemic stroke and were admitted to the ICU in the post alteplase therapy period giving an incidence of $1.98 \%$. Unfortunately, 19 of these patients did not have any documentation of their NIHSS score at admission to our ICU and hence were excluded from analysis.

Of the total 50 patients who were finally included in the study, the mean age of the patients of ischemic stroke patients was $62.8 \pm 14.6$ years. There was no statistically significant difference between the mean ages of the patients with high or low NIHSS score. Our ischemic stroke patients had preponderance of male patients with male: female ratio of 1.38:1, however this difference was not statistically significant $(\mathrm{P}=0.36)$. The ICU stay was significantly longer in patients having NIHSS score between 15-20 ( $\mathrm{P}=0.04)$ (Table-1).

None of the patients in this series had a NIHSS score $>20$. Of the 6 patients whose NIHSS score was 0 4 , only 1 developed noticeable complication in the form of minor gum bleeding that was self-limited. In contrast, we noted serious complication in 10 patients in the form of intra cranial hemorrhage. Of these, 5 patients $(50.0 \%)$ had a NIHSS score of 15 or more. 3 out of 4 deaths also happened in patients with NIHSS score 15 or more (Table-2).

Nature of systemic bleeding complications that were noted in few of our patients included mild gum bleeding, excessive bruising, nasogastric coffee ground aspirate and hematuria.

All variables were assessed for association with mortality as shown in Table-3. Logistic regression was applied for assessment of predictors of mortality and only NIHSS Score $(\mathrm{P}=0.002)$ and duration of ICU stay $(\mathrm{P}=0.001)$ were found to be independent predictors of mortality. The mean duration of ICU stay of patients who died was a mean of $833.2 \mathrm{hr}$ versus $70.1 \mathrm{hr}$ for those who survived and were discharged from the ICU.

Table-1: Showing mean age, sex, alteplase dose and ICU stay of the 50 patients in relation to their NIHSS score

\begin{tabular}{|l|l|l|l|l|l|l|}
\hline Parameter & Overall & $\begin{array}{l}\text { NIHSS Score } \\
\mathbf{0 - 4}, \mathbf{n = 6}\end{array}$ & $\begin{array}{l}\text { NIHSS Score } \\
\mathbf{1 0 - 1 4 , \mathbf { n = 2 1 }}\end{array}$ & $\begin{array}{l}\text { NIHSS Score } \\
\mathbf{1 0 - 1 4}, \mathbf{n = 1 4}\end{array}$ & $\begin{array}{l}\text { NIHSS Score } \\
\mathbf{1 5 - 2 0}, \mathbf{n = 9}\end{array}$ & \begin{tabular}{l} 
P- Value \\
\hline Mean age (yr)*
\end{tabular} \\
\hline Sex- M: F & $62.8 \pm 14.6$ & $61.6 \pm 16.1$ & $65.3 \pm 12.2$ & $62.2 \pm 16.2$ & $59.0 \pm 17.7$ & 0.749 \\
\hline Alteplase Dose (mg)* & $1.38: 1$ & $2: 1$ & $1.33: 1$ & $1.8: 1$ & $0.8: 1$ & 0.363 \\
\hline ICU Stay (hr)* & $65.4 \pm 10.9$ & $61.6 \pm 8.5$ & $67.5 \pm 11.7$ & $64.3 \pm 12.3$ & $64.5 \pm 10.7$ & 0.658 \\
\hline
\end{tabular}

* Data Presented as Mean \pm standard deviation

Table-2: Outcomes of the 50 patients whose NIHSS score were recorded in patient's file and could be analyzed for complications

\begin{tabular}{|c|c|c|c|c|c|}
\hline Outcome Measure & $\begin{array}{l}\text { NIHSS Score } \\
0-4, n=6\end{array}$ & $\begin{array}{l}\text { NIHSS Score 10- } \\
14, n=21\end{array}$ & $\begin{array}{l}\text { NIHSS Score 10- } \\
14, n=14\end{array}$ & $\begin{array}{l}\text { NIHSS Score } \\
15-20, n=9\end{array}$ & $\begin{array}{l}\text { P- } \\
\text { Value }\end{array}$ \\
\hline Systemic Bleeding & $1(16.6 \%)$ & $3(14.3 \%)$ & $3(21.4 \%)$ & $5(5 \%)$ & 0.101 \\
\hline $\begin{array}{l}\text { Intra-Cranial } \\
\text { Hemorrhage }\end{array}$ & 0 & $3(14.3 \%)$ & $2(14.3 \%)$ & $5(5 \%)$ & 0.025 \\
\hline Death & 0 & 0 & $1(7.1 \%)$ & $3(33.3 \%)$ & 0.017 \\
\hline
\end{tabular}

*Data expressed as number (percentage)

Table-3: Characteristics of patients according to outcome

\begin{tabular}{|l|l|l|l|}
\hline Parameters & $\begin{array}{l}\text { Death, } \\
\mathbf{N = 4}\end{array}$ & $\begin{array}{l}\text { Discharge, } \\
\mathbf{N = 4 6}\end{array}$ & P-Value \\
\hline Sex Ratio (M: F) & $1: 1$ & $1.42: 1$ & 0.735 \\
\hline Intra-Cranial Hemorrhage & $2(50 \%)$ & $8(17.4 \%)$ & 0.174 \\
\hline Systemic Bleeding & $2(50 \%)$ & $10(21.7 \%)$ & 0.240 \\
\hline Age (Yr)* & $57.5 \pm 27.2$ & $63.3 \pm 13.4$ & 0.698 \\
\hline Alteplase Dose (mg)* & $63.5 \pm 9.0$ & $65.5 \pm 11.2$ & 0.722 \\
\hline NIHSS Score* & $15.7 \pm 4.2$ & $8.9 \pm 4.1$ & $\mathbf{0 . 0 0 2}$ \\
\hline ICU Stay (hr)* & $833.2 \pm 166.4$ & $70.1 \pm 91.3$ & $<\mathbf{0 . 0 0 1}$ \\
\hline
\end{tabular}




\section{DISCUSSION}

The NIHSS is a scoring system to help healthcare providers to evaluate the stroke severity. The NIHSS consists of 11 items. Each of these items scores a specific ability between a 0 and 4 where 0 indicates normal function in that specific ability, while a higher score is indicative of increasing level of impairment. The NIHSS score is the summation of these individual scores. The maximum possible score is 42 , with the minimum score being a $0[6,7]$. Scores of $0,1-4,5-15$, 16-20 21-42 shows that the patient has no stroke symptoms, minor stroke, moderate stroke, moderate to severe stroke and severe stroke respectively [5].

This retrospective study revealed that patients having an NIHSS score of 0-4 have minimal chance of any serious complications. These are the patients with minor stroke as per NIHSS score [5]. We noted that the incidence of death and serious complication like intracranial hemorrhage remains largely confined to patients with an NIHSS score of 15 or more. We could therefor establish that patients with an NIHSS score 0-4 can be safely managed outside of the ICU in high Dependency Units or stroke ward and save hospital resources. However, a firmer conclusion can be reached by carrying out a study with a larger sample size.

Korean Stroke Registry analyzed 46,098 stroke patients between January 2002 and November 2010 and noted that their mean age was $66.1 \pm 12.3$ years, and $57.6 \%$ were men [8]. Tobi and Okojie too reported 55.65 of their patients to be over 60 years and mainly of the male sex $(66.7 \%)$ [9]. These findings are in agreement to the present retrospective study where the mean age of the patients was $62.8 \pm 14.6$ years and were predominantly males.

Tobie and Okojie reported a high mortality rate of nearly $78 \%$ in their ischemic stroke patients [9]. However, others have reported a much lower mortality rates in ICU patients with acute ischemic stroke [10]. This lower mortality rate is nearly identical to the findings in this retrospective study. The wide range of mortality rates may be attributed to several factors, including ICU admission criteria and percentage of patients with NIHSS score of $>16$ in the respective cohorts. In this study, mortality was highest in patients who had NIHSS score more than 15 and had a mean ICU stay of $344.0 \mathrm{hr}$.

This study had a few limitations. First, the sample size was relatively small. Second, 19/69 $(27.5 \%)$ patients did not have their NIHSS score documented in their files. Lastly, there was no meticulous long-term follow-up over time after discharge from the hospital.

\section{CONCLUSION}

ICU management should be reserved for ischemic stroke patients who have a NIHSS score of 5 or greater and are likely to develop complications like cerebral edema and elevated ICP, hemorrhagic transformation, and/or progressive ischemia. On the contrary, patients having NIHSS score of 0-4 have minimal risks of these morbidities and can be provided safe clinical management and appropriate monitoring in areas outside of the ICU like in the stroke ward or High Dependency Units thereby saving precious hospital resources.

\section{REFERENCES}

1. Bevers, M. B., \& Kimberly, W. T. (2017). Critical care management of acute ischemic stroke. Curr Treat Options Cardiovasc Med, 19(6): 41.

2. Kramer, A. H., \& Zygun, D. A. (2011). Do neurocritical care units save lives? measuring the impact of specialized ICUs. Neurocrit Care, 14:329 333.

3. Mirski, M., Chang, C., \& Cowan, R. (2001). Impact of a neuroscience intensive care unit on neurosurgical patient outcomes and cost of care: evidence-based support for an intensivist-directed specialty ICU model of care. J Neurosurg Anesthesiol 13:83-92.

4. Stroke Unit Trialists' Collaboration. (2013). Organised inpatient (stroke unit) care for stroke. Cochrane Database Syst Rev, 2013-2015.

5. National Institute of Health, National Institute of Neurological Disorders and Stroke. Stroke scale. http://ninds.nih.gov/sites/default/files/NIH_Stroke_S cale_Bookl et.pdf.

6. NIH Stroke Scale Training, Part 2. Basic Instruction. Department of Health and Human Services, National Institute of Neurological Disorders and Stroke. The National Institute of Neurological Disorders and Stroke (NINDS) Version 2.0.

7. Hage, V. (2011). The NIH stroke scale: a window into neurological status. Nursing Spectrum. 24(15): 44-49.

8. Jung, K. H., Lee, S. H., Kim, B. J., Yu, K. H., Hong, K. S., Lee, B. C., \& Roh, J. K. (2012). Korean Stroke Registry Study Group. Secular trends in ischemic stroke characteristics in a rapidly developed country: results from the Korean Stroke Registry Study (secular trends in Korean stroke). Circ Cardiovasc Qual Outcomes. 2012; 5:327-334.

9. Tobi, K. U., \& Okojie, N. Q. (2013). Characteristics and outcome of stroke patients with cerebrovascular accident at the intensice care unit of a tertiary hospital in Nigeria. J West Afr Coll Surg. 3(1): 1-13.

10. Golestanian, E., Liou, J. I., \& Smith, M. A. (2009). Long-term survival in older critically ill patients with acute ischemic stroke. Crit Care Med, 37:3107-3113. 